\title{
PROSPECTIVE MODELLING OF ENVIRONMENTAL DYNAMICS. A METHODOLOGICAL COMPARISON APPLIED TO MOUNTAIN LAND COVER CHANGES
}

\author{
Paegelow, M., Camacho Olmedo M.T., Ferraty F., Ferré L., Sarda P., Villa N.
}

*GEODE UMR 5602 CNRS, Université Toulouse - Le Mirail, Maison de la Recherche, 5 allées Antonio Machado 31058 Toulouse cedex 9, France, paegelow@univ-tlse2.fr

** Departamento de Análisis Geográfico Regional, Universidad de Granada, Campus de la Cartuja, 18077 Granada, Spain, camacho@ugr.es

\begin{abstract}
*** Institut de Mathématiques de Toulouse, Université Paul Sabatier, 118 route de Narbonne, 31062 Toulouse cedex 9, ferraty@univ-tlse2.fr, loferre@univ-

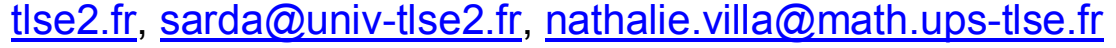

\begin{abstract}
During the last 10 years, scientists performed significant advances in modelling environmental dynamics. A wide range of new methodological approaches in geomatics - such as neural networks, multi-agent systems or fuzzy logics - was developed. Despite these progresses, the modelling softwares available have to be considered as experimental tools rather than as improved procedures able to work for environmental management or decision support. Particularly, the authors consider that a large number of publications suffer from lakes in the validation of the model results.
\end{abstract}

This contribution describes three different modelling approaches applied to prospective land cover prediction. The first one, a combined geomatic method, uses Markov chains for temporal transition prediction while their spatial assignment is supervised manually by the construction of suitability maps. Compared to this directed method, the two others may be considered as semi automatic because both the polychotomous regression and the multilayer perceptron only need to be optimized during a training step - the algorithms detect themselves the spatial-temporal changes in land cover.

The authors describe the three methodological approaches and their practical applications to two mountain studied areas: one in French Pyrenees, the second including a large part of Sierra Nevada, Spain. The article focuses on the comparison of results. The main result is that prediction scores are on the more high that land cover is persistent. They also underline that the geomatic model is complementary to the statistical ones which perform higher overall prediction rate but produce worse simulations when land cover changes are numerous.

Keywords: combined geomatic model, land cover dynamics, modelling, multilayer perceptron, polychotomous regression, validation.

\section{Resumen}

En la última década desde el ámbito científico se han producido avances significativos en la modelización de dinámicas ambientales. Se han desarrollado una gran variedad de aproximaciones metodológicas novedosas en el campo de la geomática, como las redes neuronales, los sistemas multi-agente o la clasificación borrosa (fuzzy). A pesar de este progreso, los programas de modelización hoy disponibles deben ser considerados más como herramientas experimentales que como procedimientos validados capaces de funcionar en la gestión medioambiental o en el proceso de ayuda a la decisión. En particular, los autores 
consideran que un número elevado de publicaciones adolecen de todo lo que concierne a la validación de los resultados de la modelización.

Esta contribución describe tres aproximaciones metodológicas diferentes aplicadas a la predicción prospectiva de los cambios de ocupación del suelo. El primer modelo, denominado aquí modelo geomático combinado, utiliza las cadenas de Markov para la predicción de las transiciones temporales aunque la asignación espacial se ve asistida por la elaboración de los mapas de aptitud. En comparación con este modelo asistido, los otros dos pueden ser calificados como semi-automáticos ya que tanto el modelo lineal generalizado como el modelo de redes neuronales multicapa necesitan sólo ser optimizados durante la fase de calibración los algoritmos detectan ellos mismos las estructuras de cambios espacio-temporales de la ocupación del suelo-.

Los autores describen las tres metodologías y su puesta en funcionamiento en dos zonas de montaña: una situada en los Pirineos franceses y otra que incluye parte de la vertiente sur de Sierra Nevada, en España. El artículo hace hincapié en la comparación de los resultados. Las principales conclusiones son que las tasas de predicción son mejores cuando la ocupación del suelo es estable. Se destaca también la complementariedad de los modelos semi-automáticos, que obtienen las tasas de predicción más elevadas, y del modelo geomático combinado, donde los resultados son más realistas cuando los cambios de ocupación del suelo son numerosos.

Palabras clave: dinámicas de la ocupación del suelo, modelo geomático combinado, modelo lineal generalizado, modelización, redes neuronales multicapa, validación.

\section{Résumé}

Durant les dernières dix années, les scientifiques ont accompli des avancées significatives dans la modélisation de dynamiques environnementales. Une grande variété d'approches méthodologiques novatrices en géomatique comme les réseaux neuronaux, les systèmes multi-agents ou encore la logique floue ont été développées. Malgré ces progrès, les programmes de modélisation aujourd'hui disponibles doivent plutôt être considérés comme des outils expérimentaux que comme des procédures validées capables de fonctionner en gestion environnementale et dans l'aide à la décision. En particulier, les auteurs considèrent qu'un nombre élevé de publications souffre de manques en ce qui concerne la validation des résultats de modélisation.

Cette contribution décrit trois approches modélisatrices différentes appliquées à la prédiction prospective de changements d'occupation du sol. Le premier modèle, appelé modèle géomatique combiné, utilise des chaînes de Markov pour la prédiction des transitions temporelles tandis que leur affectation spatiale est assistée manuellement par des cartes d'aptitude. Comparé à ce modèle assisté, les deux autres peuvent être qualifiés de semiautomatiques car aussi bien le modèle linéaire généralisé que le modèle par réseau neuronal multicouche nécessitent seulement une optimisation durant une phase de calibration - les algorithmes détectent eux-mêmes les structures de changements spatio-temporels de l'occupation du sol.

Les auteurs décrivent les trois approches méthodologiques et leur mise en œuvre sur deux aires d'études montagnardes: l'une située dans les Pyrénées françaises, l'autre qui inclut une grande part de la Sierra Nevada en Espagne. L'article insiste sur la comparaison des résultats. Les principaux résultats sont que les scores de prédiction sont d'autant meilleurs que l'occupation du sol est stable. Ils soulignent aussi la complémentarité des modèles semiautomatiques qui obtiennent des scores de prédiction plus élevés et du modèle géomatique combiné dont les résultats sont plus réalistes lorsque l'occupation du sol change beaucoup.

Mots clefs: dynamiques d'occupation du sol, modèle géomatique combiné, modèle linéaire généralisé, modélisation, perceptron multi-couches, validation.

\section{Introduction}

This paper focuses on the comparison of the results of three modelling approaches applied to land cover prediction in Mediterranean mountains. The studied areas are located in French Eastern Pyrenees (Garrotxes) and the south side of Sierra Nevada in Spain (Alta 
Alpujarra Granadina). The methodological approaches used for modelling the land cover are a combined geomatic model, based on Markov chain analysis, fuzzy logic and a cellular automaton, a linear parametric model (polychotomous regression modelling) and a neural network (multilayer perceptron).

Based on former publications (Paegelow et al, 2002, 2003, 2004; Paegelow, 2003; Paegelow and Camacho, 2003, 2004) informing on results of only one model or applied to one data set, we intend here to cross the obtained results with the aim to undertake an in-depth comparison. In author's mind, this validation step is important for two reasons. First, it permits to evaluate the degree of performance of any model. Only a meticulous validation may help to better understand the analyzed dynamic process and to line out the limits and the abilities of the modelling approach. Often, this aspect is neglected in scientific articles. Then, a discussion of combined results and validation indices is useful to know the advantages and weak points of each model in order to aggregate them into a better model.

We undertake prospective land cover modelling with a thin spatial resolution (grid cells have a length of about $20 \mathrm{~m}$ ) and temporal intervals (that are about one to two decades). This means extrapolation over space and time in the context of complex social and environmental systems. In this framework, the main problems are a nonlinear behaviour, a high number of relevant criteria but a low number of available dates. Moreover, we remark various inertia of land cover subject to human activities and to natural factors spread out in space.

Basically land cover modelling means time interpolation or extrapolation when the modelling exceeds the known period. Prospective modelling is the prediction of a future state. Tools for time modelling only appeared in GIS during the last years and should be considered as interesting and experimental algorithms rather than improved and operational tools for decision support. At the same time the social supply for decision support and modelling tools is increasing quickly so as to be able to help different management tasks like risk prevention, land planning and environmental management.

Among methodological approaches for prospective modelling of high resolution land cover data, we distinguish between automatic and supervised models. We call automatic a model that analyzes the relationships among the training data (i.e. land cover training maps and land cover relevant criteria also coming from the training period) in order to carry out a spatiotemporal simulated map at a close date. In the case of a supervised model, a specialist has to give some information about the suitability of spatial location and time transition. The results of this thematic analysis assist the modelling process which leads to an approach similar to decision support. In practice, many models, like our geomatic approach, mix automatic and directed aspects. The presented model uses an automatic (markovian) procedure to compute time transition probabilities but a geographic directed analysis to establish the land cover suitability used for spatial assignment of predicted time transitions. In this context, we can cite various methods based on fuzzy logic (Zadeh, 1988) often used in the context of GIS (Mezzadri-Centeno, 1998) or on remote sensing data (Selleron and Mezzadri-Centeno, 2002). Other models are almost totally automatic with a supervising of the optimisation some parameters. This is the case of statistical approaches by neural networks (Bishop, 1995; Parlitz and Merkwirth, 2000), particularly perceptron with one or more hidden layers. During the training phase of the model, the weights of the perceptron are chosen to minimize the quadratic error on the training data set. These neural multilayer networks are able to approach with a chosen precision any smooth function (universal approximation) (Hornik, 1993). Generalized linear models are another interesting approach based on a special case of the logistic regression, the polychotomous regression, where the qualitative predicted variable may have more than two values (Koopersberg et al, 1997). The polychotomous regression needs also a training phase to be optimized: the Newton-Raphson algorithm is generally used to perform this optimization. 


\section{Test areas and data sets}

\subsection{Test areas}

To minimize the influence of a specific data set, we analyzed two test areas: Garrotxes (French Eastern Pyrenees) and Alta Alpujarra Granadina (Spain, Andalusia, Sierra Nevada) (Paegelow and Camacho, 2003).

European mountain areas are affected by a deep social and economic reorganization which leads to major changes in the landscape. In French Pyrenees, the maximum of human activity and population density corresponds to the beginning of the $19^{\text {th }}$ century. In the French studied area, changes began around 1850 with the decline of the traditional agro pastoral economy and an important rural exodus. Cropland was transformed into pastures and later, often became colonized by forests again. The Andalusian site had the same decrease but also a more substantial economic reorganization.

Garrotxes (Figure 1) is a $8 \sim 750$ ha catchment area located in the western part of the department of Eastern Pyrenees (France). The difference of height between the main summit at the north extremity (Madrès, $2469 \mathrm{~m}$ ) and the confluence of the Cabrils on the south east border of the map $(650 \mathrm{~m})$ is important. On the right side, characterized by a ponderous geomorphologic relief based on granite, the space has a fast dynamic vegetation: almost all earlier terrace cultivations and coniferous forests (Pinus uncinata) are situated here. The left bank forms a large, steep and south facing side on schist used as pasture. At the demographic maximum (1820/30) all natural resources were used intensively. In 1826, $25 \%$ of the whole area was developed as crop terraces (Napoleon cadastre of 1826). The population pulled down from 1832 inhabitants in 1826 to about 90 inhabitants today. Crop terraces were transformed to pastures and became, later, bushes or forests. Actually the crops are completely marginal and the near future depends on the intensity of pastoral activities and on the management from which the extent of spontaneous forest spreading depend (Métailié and Paegelow, 2004).

Alta Alpujarra Granadina (34 500 ha) forms the western part of the south side of Sierra Nevada (Spain); a region with a characteristic landscape (Camacho et al, 2002a, 2002b, 2002c; Camacho, 2003) for which historical evolution is documented up from the $15^{\text {th }}$ century (García, 1999). The latitudinal shift to the Pyrenees is made off partially by the important difference of height $(2900 \mathrm{~m})$. The southern limit $(600 \mathrm{~m})$ is close to Guadelfeo, a river separating the studied area from Contraviesa. The northern limit is made by the highest summits of the lberian Peninsula: Mulhacen ( $3479 \mathrm{~m}$ ) and Veleta (3 $396 \mathrm{~m}$ ). During the past 40 years, the population pulled down from 4200 to 1200 today. The proximity to urban centres (Granada, Alméria or Malaga) explains the great development of rural tourism.

The maximal use of natural resources occurred at the end of the $19^{\text {th }}$ century followed by a progressive decrease of agriculture. It only stopped during the 1940s (period of economic autarky). Up from the beginning of the 1960s the rural exodus became general in Spanish mountains with a successive desertion of non irrigated land and irrigated land located at high altitudes. This process is followed by a (semi) desertion of irrigated lands which are located at a lower level. The transformation of croplands into fallow lands leads to a landscape homogenization. In the regional context, Alta Alpujarra Granadina is a significant example of this intensive process of desertion.

Fig. 1: Location of the studied areas: Garrotxes (top) and Alta Alpujarra Granadina (bottom) 


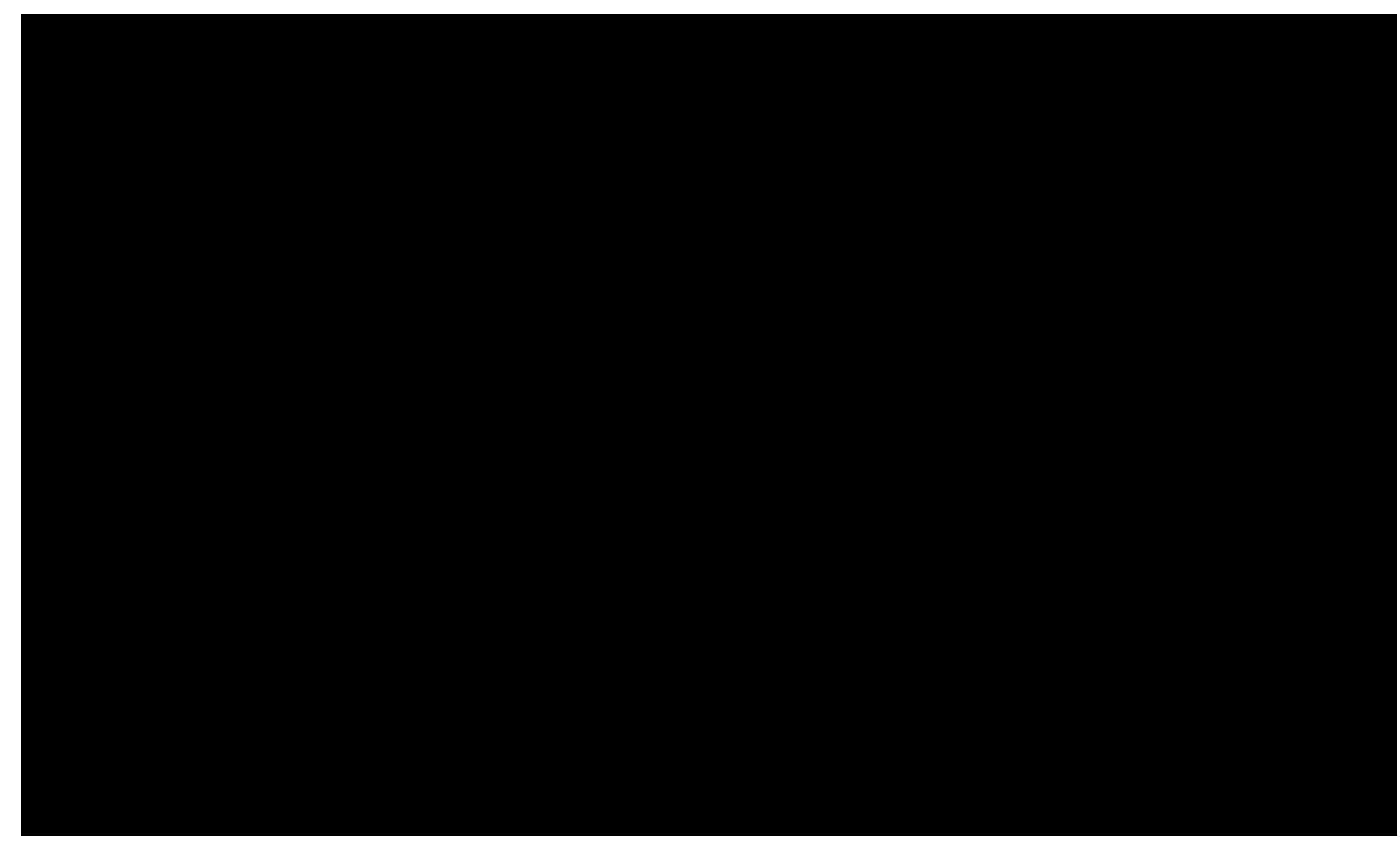

\subsection{Data sets}

The GIS data base includes several maps with available land cover layers and relevant environmental and social factors (elevation, slope, orientation, accessibility cost maps, hydrographs, geomorphology, administrative limits and informations about management status of particular areas such as public forests or pasture management).

Land cover layers come from many sources (Napoleon cadastre, aerial photographs and manual maps on the French site; aerial photographs, thematic maps and manual maps in 
Spain) and illustrate the historical evolution as early as possible: 6 land cover maps in Garrotxes (1826, 1942, 1962, 1980, 1989, 2000), 4 in Alta Alpujarra (1957, 1974, 1987, 2001). The land cover maps of Garrotxes come from various sources and have various land cover layers: the first land cover map (1826), which has been built from the Napoleon cadastre, allows distinguishing forest, pasture, grassland, agriculture and urban use. First aerial photographs (1942) permit to insert a category between pasture and forest: scrubs. The land cover map of 1962 has the same layers, while the scale and quality of later aerial photographs allows distinguishing deciduous from coniferous forests and broom lands from grass-based pastures $(1980,1989$, and 2000). For modelling, we use only the latest three dates; earlier land cover reflects social and economic conditions to far from actual reality.

The Spanish land cover maps contain various levels of details. For this work, we used a simplified version with the same caption for all dates.

Land cover changes during the studied period are dramatic as shown in Figures $\mathbf{2}$ and $\mathbf{3 .}$ In Garrotxes we can notice that crops (terrace cultivating), that used to take up $25 \%$ of the area in 1826, have almost disappeared in the early 1980s. They first became pastures and then scrubs and forests. In Alta Alpujarra Granadina, the cultivated lands pulled down from $21.9 \%$ of the area in 1957 to $7.1 \%$ today. The irrigated land decreased from $14.6 \%$ to $5.8 \%$ of the area but proportionally increased from $66.7 \%$ to $81.7 \%$ of the overall agricultural activities. Because the vegetal growth is very slow, the fallows became one of the major land cover of the area. Another important evolution is that coniferous forests increased twofold on high elevation sides. 
Fig. 2: Net quantity changes for land cover in Garrotxes (France): 1826 - 2000

Fig. 3: Net quantity changes for land cover in Alta Alpujarra Granadina (Spain): 1957 - 2001 (data for Mosaic of cropland and fallows are not available in 1974) 


\section{Methodology and practical application to the data sets}

\subsection{Models}

Three different models were applied to the two data sets. They have common features: maps have been set at almost equidistant dates and the list of all possible transitions is finite and related to the land cover captions. Each tested model uses exactly the same data (two earlier land cover maps and several relevant criteria) to train the model (calibration). The prospective simulation is made for the latest known land cover state which is unknown by the models and only used for validation.

The first method, called combined geomatic model, is based on available GIS software modules. Time transition probabilities result from Markov chain analysis but the spatial assignment of the simulated land cover is assisted by a set of suitability maps, one for each land cover which expresses geographic knowledge and is performed manually by an expert.

In order to propose automatic alternatives to the GIS, two approaches have been adapted to estimate the evolution of the land cover: the first one, the polychotomous regression modelling, is a generalized linear model with estimation based on the maximum log-likelihood method. The second one, the multilayer perceptron, is a popular method which has recently proved its great efficiency to solve various types of problems.

The idea is to confront a parametric linear model with a nonparametric one to provide a collection of automatic statistical methods for geographers. They both have concurrent advantages that have to be taken into account when choosing one of them: the polychotomous regression modelling is faster to train than multilayer perceptrons, especially in high dimensional spaces and does not suffer from the existence of local minima. On the contrary, multilayer perceptrons can provide nonparametric solutions and then, they are more flexible; Both methods are easy to implement, even for non statisticians, through the pre-made softwares (for example, "Neural Network" Toolbox for neural networks with Matlab).

\subsubsection{Combined geomatic model}

\section{Construction of a knowledge base - multi criteria evaluation (MCE)}

The knowledge about former dynamics is essential for attempting to predict the future evolution or to build prospective scenarios. Therefore each model has to be supplied with the values of the initial conditions (calibration). For this step, we used the two training land cover maps used to perform time transition probabilities and criteria which are correlated to land cover. Statistical procedures (logistic regression, PCA) helped us to choose the criteria which are relevant. We only used easily available data in order to provide a model that can be generalized.

The criteria were split up into Boolean constraints (a specific land cover is allowed or not) and factors which express the level of suitability for each land cover; this level depends of the localization of the pixel. The constraints simply masked some areas of the map while the factors were weighted in order to permit a tradeoff between each others. The result of this multi criteria evaluation is a set of suitability maps showing terrain suitability for each land cover. These maps assist the spatial assignment of time transition probabilities performed by Markov chain analysis.

\section{Computing time transition probabilities - Markov chain analysis (MCA)}

To perform land cover extrapolation, we used a Markov chain analysis (MCA), a discrete process for which values at instance $t_{1}$ depend on values at instances $t_{0}$ (Markov chain of order 1). The prediction was given as an estimation of the transition probabilities.

MCA produced a transition matrix which contains the probability that each land cover will change to each other land cover: we can then deduce the number of pixels expected to change. The algorithm also generated conditional probability maps for each land cover after a specified number of time units. 


\section{Spatial assignment of predicted land cover probabilities - multi objective evaluation (MOE) and cellular automaton (CA)}

The integrating step, combining knowledge about likely spatial distribution (MCE), time transition probabilities (MCA) as well as multi-objective land allocation, was performed by multi objective evaluation (MOE) using the amount of expected changes and MCE results. The land cover prediction procedure finally added spatial contiguity constraints. The cellular automaton (CA) is based on a standard contiguity filter $(5 \times 5)$ to down-weight the suitability of the pixels that are distant from existing instances of the land cover type under consideration. The algorithm is iterative so as to match with time distances between $t_{-1}-t_{0}$ and between $t_{0}-t_{-1}$.

\subsubsection{Polychotomous regression modelling}

When we wish to predict a categorical response given a random vector, a useful model is the multiple logistic regression (or polychotomous regression) (Lai and Wong, 2001). A smooth version of this kind of method can be found in Kooperberg et al. (Koopersberg et al, 1997). Applications of these statistical techniques to several situations such as medicine or phoneme recognition can be found in these two papers. Their good behaviour, both on theoretical and practical grounds, has been emphasized. In our case, the predictors are both categorical and scalar and then we have the derived model below:

Let us note, for $k=1, \ldots, k$,

$$
\theta\left(C_{k} \mid X_{i, j}(t)\right)=\log \frac{P\left(c_{i, j}(t)=C_{k} \mid X_{i, j}(t)\right)}{P\left(c_{i, j}(t)=C_{K} \mid X_{i, j}(t)\right)}
$$

where $C_{1}, \ldots, C_{k}$ are the different values of the land cover, cii(t) is the value of land cover for pixel $(I, j)$ at time $t$ and $X_{i, j}(t)$ is the vector of social factors as well as values of land cover in the neighbourhood of pixel $(i, j)$ at time $t-1$. Then, we get the following expression

$$
P\left(c_{i, j}(t)=C_{k} \mid X_{i, j}(t)\right)=\frac{\exp \theta\left(C_{k} \mid X_{i, j}(t)\right)}{\sum_{j=1}^{k} \exp \theta\left(C_{j} \mid X_{i, j}(t)\right)}
$$

Now, to estimate these conditional probabilities, we use the parametric approach to the polychotomous regression problem that is the linear model

$$
\theta\left(C_{k} \mid X_{i, j}(t)\right)=\alpha_{k}+\sum_{c \in V_{i, j}(t-1)} \sum_{l=1}^{K} \beta_{k} I_{[c=l C]}+\sum_{r=1}^{p} \gamma_{k r} Y_{i, j}
$$

where $V_{\mathrm{ij}}(\mathrm{t}-1)$ are the values of the land cover in the neighbourhood of the pixel $(i, j)$ on the previous date $t-1$ and $\left(Y_{i, j}^{r}\right)$, are the values of the environment variables. Let us call $\delta=\left(\alpha_{1}, \ldots\right.$, $\left.\alpha_{k-1}, \beta_{1,1}, \ldots, \beta_{1, k}, \beta_{2,1}, \ldots, \beta_{2, k}, \ldots, \beta_{k-1, k}, \gamma_{1,1}, \ldots, \gamma_{1, k}, \ldots, \gamma_{k-1,1}, \ldots, \gamma_{k-1, p}\right)$, the parameters of the model to be estimated. We have to notice that we have $\alpha_{k}=0, \beta_{k, l}=0$ for all I $=1, \ldots, K$, and $\gamma_{k, r}$ $=0$ for all $r=1, \ldots, p$. We now have to estimate the vector of parameters $\delta$. For this, we use a penalized likelihood estimator which is performed on the training sample. Let us write the penalized log-likelihood function for model (3). It is given by

$$
I_{\epsilon}(\delta)=I(\delta)-\epsilon \sum_{n=1}^{N} \sum_{k=1}^{K} u_{n k}^{2}
$$

where the log-likelihood function is 


$$
I(\delta)=\log \left(\prod_{n=1}^{N} P_{\delta}\left(c^{(n)} \mid X^{(n)}\right)\right)
$$

In this expression, $P_{\delta}\left(c^{(n)} \mid X^{(n)}\right)$ is the value of the probability given by (2) and (3) for the observations $\left(X^{(n)}, c^{(n)}\right)$ and the value $\delta$ of the parameter. In expression $(5), \varepsilon$ is a penalization parameter and, for $\mathrm{k}=1, \ldots, \mathrm{K}$,

$$
u_{n k}=\theta_{\delta}\left(Q_{k} X^{\prime}\right)-\frac{1}{K} \sum_{j=1}^{K} \theta_{\delta}\left(Q_{j}\right) .
$$

Our penalized likelihood estimator ` $\xi$ satisfies:

$$
\hat{\delta}_{\epsilon}=\operatorname{argmax}{ }_{\delta \in R^{n}} I_{\epsilon}(\delta)
$$

where $\mathrm{M}=\mathrm{K}^{2}+(\mathrm{K}-1){ }^{*} \mathrm{p}-1$ denotes the number of parameters to be estimated.

As pointed out by Kooperberg et al. (1997), in the context of smooth polychotomous regression without the penalty term, the maximization of the log-likelihood function $/ \delta$ ) can lead to infinite coefficients $\beta_{\mathrm{kl}}$. In our model, it may be the case, for example, when, for fixed $k$, the value of the predictor is equal to zero for all $(i, j)$. Actually, this "pathological" case can not really occur in practice but for classes $k$ with a few number of members, the value of the predictor is low and then a numerical instability happens when maximizing the log-likelihood. Then, the form of the penalty based on the difference between the value $\theta_{\varphi}\left(\xi_{k} \mid X^{(n)}\right.$ for class $k$ and the mean over all the classes has the aim of preventing this instability by forcing $\theta_{\varphi}\left(\xi_{k} \mid X^{(n)}\right.$ to be not too far from the mean. On another side, for reasonable values of $\varepsilon$, we can expect that the penalty term does not affect so much the estimation of parameters while it guarantees numerical stability. Finally, numerical maximization of the penalized log-likelihood function is achieved by a Newton-Raphson algorithm.

\subsubsection{Multilayer perceptron}

Neural networks have a great adaptability to any statistical problems and especially to overcome the difficulties of nonlinear problems even if the predictors are highly correlated; thus it is not surprising to find them used in the chronological series prediction Bishop, 1995; Parlitz and Merkwirth, 2000; Lai and Wong, 2001). The main interest of neural networks is their ability to approximate almost any function with the desired precision (universal approximation) (see, for instance, Hornik, 1991).

Here, we propose to estimate the function $P\left(c_{i j}\left(t\left|=C_{k}\right| X_{i j}(t)\right)\right.$ in (1) in the form of a multilayer perceptron $\Psi$ with one hidden layer (Figure 4). This multilayer perceptron is a function from $R^{q}$ to $\mathrm{R}$ that can be written, for all $\mathrm{x}$ in $\mathrm{R}^{\mathrm{q}}$, as

$$
\Psi_{w}(x)=\sum_{i=1}^{q_{2}} w_{i}^{(2)} g\left(\left\langle x, w_{i}^{(1)}\right\rangle+w_{i, 0}^{(1)}\right)
$$

where $q_{2}$ in $\mathrm{N}$ is the number of neurons on the hidden layer, $\left(\mathrm{w}_{i}^{(1)}\right)_{i=1}, \ldots, q 2$

(respectively, $\left.\left(w_{i}^{(2)}\right)_{\mathrm{i}=1}, \ldots, \mathrm{q} 2 ;\left(\mathrm{w}_{\mathrm{i}, 0}{ }^{(1)}\right)_{\mathrm{i}=1}, \ldots \mathrm{q} 2\right)$ are in $\mathrm{R}^{\mathrm{q}}($ resp. $\mathrm{R})$ and are called weights and bias, and where $g$, the activation function, is a sigmoïd; for example, $g(x)=1 /\left(1+e^{-x}\right)$.

Then, the output of the multilayer perceptron is a smooth function (here it is indefinite continuous and derivable) of its input. This property ensures that 
Fig. 4: Multilayer perceptron with one hidden layer

the neural network took into account the spatial aspect of the data set, since two neighbouring pixels have "close" values for their predictor variables.

To determine the optimal value for weights $w=\left(\left(w_{i}^{(1)}\right)_{i},\left(w_{i}^{(2)}\right)_{i},\left(w_{i, 0}{ }^{(1)}\right)_{i}\right)$, we minimized the quadratic error on the training sample, as it is usual: for all $k=1, \ldots, K$, we chose

$$
w_{o p t}^{k}=\operatorname{argmin}_{w \in R^{p^{(q-2)}}} \sum_{k=1}^{K}\left[c_{k}^{(n)}-\Psi_{w}^{k}\left(X^{(n)}\right)\right]^{2,}
$$

where $\mathrm{c}^{(\mathrm{n})}$ and the categorical data in $\mathrm{X}^{(\mathrm{n})}$ are written on a disjunctive form. This can be performed by classical numerical methods of the first or second order (such as gradient descent, conjugate gradients, etc.) but faces local minima problems. We explain in section 3.2.2 how we overcame this difficulty. Finally, White (White, 1989) gives many results that ensure the convergence of the optimal empirical parameters to the optimal theoretical parameters.

\subsection{Practical application to the data sets}

The three models use exactly the same data.

Calibration / training period or dates

The models were calibrated by two or three earlier land cover maps (1980 and 1989 for French Pyrenees; 1957, 1974 and 1989 for Spanish Sierra Nevada) and related maps of relevant criteria. The last known land cover map is unknown to the models and has been used for the comparison of the models.

\subsubsection{Combined geomatic model}

This model was implemented with GIS functions available in Idrisi Kilimanjaro software. 
In order to assist spatial assignment of transition probabilities, we performed a list of constraints: some of them are common to any land cover like stability of developed areas (villages); others are specific to any land covers (e.g. elevation limits the forests, distance to roads the crops, accessibility level the grassland and public woods are forbidden in pasture). These constraints are expressed in a binary form which allows, or not, a given land cover to be predicted. Another sort of criteria is factors which express the local degree of suitability for each land cover. Figure 5 gives the six original factors selected for the French area and the technique to convert them into suitability levels. The list is short for two reasons: first, we want to perform a simple model which may be implemented easily. Then, getting high resolution data can be hard.

Elevation, slope and aspect are important physical factors. The accessibility to roads and villages is a cost factor expressing the time needed to access any place. In the studied areas, the transport is exclusively road based and people live in grouped residential areas. The accessibility map results from a cost distance analysis where the usual distance is weighted by the quality of roads. The proximity to existing land cover features is the distance (average and standard variation) of each land cover to borders of land cover of the same type during the training period. It takes into account border dynamics and spontaneous appearances (which are not induced by borders). This factor is important in rural and mountain areas where forest spreading is a widespread process. The probability for each change was worked out by cross tabulation of observed land cover dynamics into the training period.

Fig. 5: Factors used and involved techniques to process suitability

\begin{tabular}{|c|c|}
\hline Factor & Technique to process suitability \\
\hline Elevation & \multirow{4}{*}{$\begin{array}{l}\text { Manual recoding based on significant (99\% and } 99.9 \% \\
\text { level) differences between real and theoretic distribution }\end{array}$} \\
\hline Slope & \\
\hline Aspect & \\
\hline Accessibility to roads and villages (cost distance) & \\
\hline Probability for land cover change & Stretching of observed transitions during $t_{-1}-t_{0}$ \\
\hline Proximity to existing land cover features (distance) & $\begin{array}{l}\text { Fuzzy function based on observed distance parameters } \\
\text { for border and spontaneous appearances }\end{array}$ \\
\hline
\end{tabular}

Because each factor was expressed in its own unit, they had to be standardized: the original values (degrees, meters, per cent) were re-scaled into suitability values on a common scale reaching from 0 (lowest suitability) to 255 (best suitability). This standardization was processed on different ways: for each land cover, the suitability of elevation, slope, aspect and accessibility was carried out by analyzing the statistical significance of the spatial dependency versus a null hypothesis. Non significant differences (less than a level of $99 \%$ mean an average suitability (128). For smaller significant levels, the suitability is also smaller and vice versa.

Once standardized, the factors were weighted using Saaty matrix (Saaty, 1977). This matrix contains the correlation of each pair of factors and a weight was deduced from it by eigenvalue decomposition.

Finally, Ordered Weighted Averaging (OWA) (Yager, 1988) allowed the choice of a risk and of tradeoff levels. "Tradeoff" means the possibility to compensate a low suitability score of one factor by a high suitability score of another factor. A tradeoff level is related to a risk level (see Figure 6) which goes from And (risk adverse) to Or (maximum risk). The fuzzy axis of risk levels is called andness. Finally, the number of order weights is equal to the number of factors and the weights sum to 1 . Order weights are calculated for each pixel and the first order weight is assigned to the factor with the lowest weighted suitability. The last order weight is assigned to the highest suitability among the weighted factors for the given pixel. 
Authors chose a strategy which may be considered as having low risk and a tradeoff illustrated in Figure 6 . The results of multi-criteria evaluation with ordered weighted averaging (MCE-OWA) are expressed as a land cover suitability map one for each caption.

Fig. 6: Space of decision strategy and chosen approach into MCE-OWA. Order weights used: $0.45,0.20,0.15,0.10,0.07,0.03$

Time transition probabilities

The prediction was performed by a Markov function from the two calibration dates .

Spatial allocation of predicted land cover probabilities

MOE and a cellular automaton are included in the CA_Markov module. For more details about practical application of the geomatic model, see Paegelow and Camacho (2005).

\subsubsection{Polychotomous regression modelling and multilayer perceptron}

In order to compare the two automatic approaches, we applied the same methodology: first we determined the optimal parameters for each approach (training step, see below) and then, we used the land cover maps to predict the last one and we finally compared this simulated maps to the real one (validation step, cf. section 5).

As usual in statistical methods, there is two steps in the training stage: the estimation step and the validation step.

The estimation step consists in estimating the parameters of the models (either for the polychotomous regression or the neural network).

The validation step allows us to choose, for both methodologies, the best neighbourhood, for polychotomous regression, the penalization parameter and, for neural network, the number of neurons on the hidden layer. We only considered square shaped neighbourhood so, here, choosing a neighbourhood is equivalent to determine its size.

For the Sierra Nevada, we saw that large areas are stable, thus we only used the pixels for which one neighbour, at least, has a different land cover. These pixels are called "frontier pixels"; the others were considered as stable (Figure 7). For the generalized linear model, we used the whole frontier pixels of the 1957/1974 maps for the estimation set and the whole 1974/1987 maps for the validation set. We then constructed the estimated 2001 map from the 1987 one. For the multilayer perceptron, we reduced the training set size in order not to have huge computational times when minimizing the loss function. Then, estimation and validation data sets were chosen randomly in the frontier pixels of the 1957/1974 and 1974/1987 maps. 
Fig. 7: Frontier pixels (order 4) for the 1957 map (Alta Alpujarra Granadina)

For the Garrotxes data set, due to the fact that we only had got 3 maps and much less pixels, we had to use the 1980/1990 maps for the estimation step (only their frontier pixels for the MLP) and the whole 1990/2000 ones for the validation step. This led to a biased estimate when constructing the 2000 map from the 1990 map but, as our purpose is to compare two models and not to make significant the error rate, we do not consider this bias as important.

\section{Polychotomous regression modelling}

- The estimation step produces the estimated parameter vector $\xi$ of the parameters $\delta$ of model (3) for a given neighbourhood and a penalization parameter $\varepsilon$. This step was repeated for various values concerning both neighbourhood and penalization parameter.

- Validation step: Once given an estimated parameter vector $\hat{\delta_{\epsilon}}=\left(\hat{\alpha_{1}}, \ldots, \hat{\alpha_{K-1}}, \hat{\beta_{1,1}}, \ldots, \hat{\beta_{1, K}}, \hat{\beta_{2,1}}, \ldots, \hat{\beta_{2, K}}, \ldots, \hat{\beta_{K-1,1}}, \ldots, \hat{\beta_{K-1, K}}, \hat{\gamma_{1,1}}, \ldots, \hat{\gamma_{K-1, p}}, \hat{\text { the }}\right.$ quantities

$$
\hat{P}\left(c_{i, j}(t)=C_{k} \mid X_{i, j}(t)\right)=\frac{\exp \hat{\theta}\left(C_{k} \mid X_{i, j}(t)\right)}{\sum_{j=1}^{K} \exp \hat{\theta}\left(C_{j} \mid X_{i, j}(t)\right)}
$$

were calculated, for all $k=1, \ldots, K$, with

$$
\hat{\theta}\left(C_{k} \mid X_{i, j}(t)\right)=\hat{\alpha}_{k}+\sum_{c \in V_{i, j}(t)} \sum_{l=1}^{K} \hat{\beta}_{k} I_{[c=l C]}+\sum_{r=1}^{p} \hat{\gamma}_{k r} Y_{i, j}^{r}
$$

At each pixel $(i, j)$ for the predicted map on date $t$, we affected the most probable land cover type, namely the $\xi_{\mathrm{k}}$, which maximizes

$$
\left\{\hat{P}\left(c_{i, j}(t)=C_{k} \mid X_{i, j}(t)\right)\right\}_{k=1, \ldots, k}
$$


Programs were made using $R$ program ( $R$ Development Core Team, 2005) and are available on request.

\section{Multilayer perceptron}

We used a neural network with one hidden layer having $q_{2}$ neurons (where $q_{2}$ is a parameter to be calibrated). The inputs of the multilayer perceptron were:

For the time series, the disjunctive form of the value of the pixel;

For the spatial aspect, the weighted frequency of each type of land cover in the neighbourhood of the pixel;

The environmental variables. two stages:

The output was the estimation of the probabilities (1). The estimation was also made in

[1] The estimation step produces the estimated weights as described in (6) for a given number of neurons $\left(\mathrm{q}_{2}\right)$ and a given neighbourhood. For this step, the neural network was trained with an early stopping procedure which allows stopping the optimization algorithm when the validation error (calculated on a part of the data set) is starting to increase (Bishop, 1995). This step was repeated for various values of both neighbourhood and $\mathrm{q}_{2}$.

[2] Validation step: once an estimation of the optimal weights was given, we chose $q_{2}$ and the size of neighbourhood, as for the previous model. Moreover, in order to escape the local minima during the training step, we trained the perceptrons many times for each value of neighbourhood and of $\mathrm{q}_{2}$ with various training sets; the "best" perceptron was then chosen according to the minimization of the validation error among both the values of the parameters (size of the neighbourhood and $\mathrm{q}_{2}$ ) and the optimization procedure results.

Programs were made using Matlab (Neural Networks Toolbox, see Beale and Demuth, 1998) and are also available on request.

\section{Results}

We applied the three models previously described and obtained simulated land cover mapsat 2000 for the Garrotxes. We found similar maps for the three methodologies and these maps are also close to reality (Figure 8). The overall good prediction rates are about $73-74 \%$ (Figure 10).

For the Spanish test area, the results (Figure 9) are closer to reality but also less easily interpretable. The comparison with real land cover in 2001 shows an overall prediction rate of $78.9 \%$ for the combined geomatic model and about $90 \%$ for the two semi-automatic models (91\% for the polychotomous regression model; $88.7 \%$ for the multilayer perceptron model) (Figure 11).

Fig. 8: Predicted land cover by combined geomatic model, polychotomous regression model and multilayer perceptron model for Garrotxes in 2000 and real land cover 
Fig. 9: Predicted land cover by combined geomatic model, polychotomous regression model and multilayer perceptron model for Alta Alpujarra Granadina in 2001 and real land cover

Fig. 10: Misclassification rates for the Garrotxes

\begin{tabular}{lcccc}
\hline Land cover & Frequency & $\begin{array}{c}\text { Combined } \\
\text { geomatic model }\end{array}$ & $\begin{array}{c}\text { Polychotomous } \\
\text { regression model }\end{array}$ & $\begin{array}{c}\text { Multilayer } \\
\text { perceptron } \\
\text { model }\end{array}$ \\
\hline types & in the area & error rate & error rate & error rate \\
\hline Coniferous forest & $40.9 \%$ & $11.4 \%$ & $11.9 \%$ & $10.6 \%$ \\
\hline Deciduous forest & $11.7 \%$ & $55.3 \%$ & $51.7 \%$ & $45.8 \%$ \\
\hline Scrubs & $15.1 \%$ & $51.9 \%$ & $57.1 \%$ & $54.5 \%$ \\
\hline Broom lands & $216 \%$ & $17.1 \%$ & $14.4 \%$ & $16.2 \%$ \\
\hline Grass pasture & $5.7 \%$ & $54.4 \%$ & $59.2 \%$ & $59.4 \%$ \\
\hline Grassland & $4.8 \%$ & $30.4 \%$ & $25.6 \%$ & $19.3 \%$ \\
\hline Overall & & $27.2 \%$ & $27.2 \%$ & $25.7 \%$ \\
\hline
\end{tabular}


Figure 11: Misclassification rates for the Alta Alpujarra Granadina

\begin{tabular}{lcccc}
\hline Land cover & Frequency & $\begin{array}{c}\text { Combined } \\
\text { geomatic model }\end{array}$ & $\begin{array}{c}\text { Polychotomous } \\
\text { regression model }\end{array}$ & $\begin{array}{c}\text { Multilayer } \\
\text { perceptron } \\
\text { model }\end{array}$ \\
\hline types & in the area & error rate & error rate & error rate \\
\hline Deciduous forests & $10.9 \%$ & $14.3 \%$ & $3.5 \%$ & $2.6 \%$ \\
\hline Scrubs & $33.0 \%$ & $15.2 \%$ & $3.1 \%$ & $1.4 \%$ \\
\hline Pasture & $20.8 \%$ & $12.5 \%$ & $0.6 \%$ & $0 \%$ \\
\hline Coniferous refor. & $9.2 \%$ & $1.9 \%$ & $3.5 \%$ & $16.3 \%$ \\
\hline Fallows & $18.8 \%$ & $46.8 \%$ & $32.5 \%$ & $41.4 \%$ \\
\hline Irrigated cropland & $5.8 \%$ & $38.9 \%$ & $8.9 \%$ & $6.8 \%$ \\
\hline Overall & & $21.1 \%$ & $9.0 \%$ & $11.3 \%$ \\
\hline
\end{tabular}

The simulation results are always closer to reality for the Alta Alpujarra Granadina as for the Garrotxes. Land cover of the Spanish test area is also more persistent in time. In Garrotxes, $75.5 \%$ of the area was persistent during the training period (1980 - 1989), $72 \%$ between 1989 and 2000 . The Spanish area stability is about $90.4 \%$ during the training period (1957 - 1987) and concerns $83.9 \%$ of the area between the last date and the previous one $(1987-2001)$.

The results show also similar misclassification rates of the three models in the French test area but misclassification rates of the combined geomatic model are higher as those performed by the polychotomous regression model and the multilayer perceptron model in the Spanish test area. We think that this difference of prediction performances is related to higher persistence rate for the Alta Alpujarra Granadina (Ferraty et al, 2005, Villa et al, 2006). This will be discussed in chapter 5 .

Another interesting result is that, the amount of predicted land cover (sum of pixels predicted without location) matches well with the reality and this for all land cover values and all models. Therefore, Figure 12 shows the worst cases (the highest overall misclassification rates obtained by the combined geomatic model compared to reality for the Garrotxes).

Fig. 12: Matrix comparing real land cover in 2000 (rows) to land cover predicted by the combined geomatic model in 2000 (columns) in Garrotxes. Data are expressed in per cent of the total area.

\begin{tabular}{l} 
Garrotxes \\
\hline
\end{tabular}

Figure 12 also shows that the model fits better to reality for the land cover values covering large areas like coniferous forests and broom lands. The prediction rate is lower for land cover values covering little areas and gets close to zero for crops that cover only $0.007 \%$ 
of the area (16 pixels). On the contrary, developed areas (urban) corresponds, by definition (constrained area), to reality. The confusion matrix for the Alta Alpujarra Granadina confirms the observed trends based upon the French study area.

\section{Validation and discussion of results}

The performed results do not intend to predict future reality but they can help us to better understand environmental and social complex changes in time and space. Therefore the interpretation must be done carefully; the land cover modelling means simulation showing what could be reality. It is a scenario in the framework of a decision support. Nevertheless, an accurate interpretation may be useful to improve the prediction rate. On both areas, good predictions are about $3 / 4$ of the whole area. In the following discussion, we will focus on the misclassified areas in order to understand the lakes in modelling and to improve future simulations. At this point, it is important to say that each model is affected by random noise. Random phenomenoms like forest fires and wind falls in Garrotxes, seem impossible to model correctly, even if they are not significant (less than $2 \%$ of the whole area). In the Spanish area, the same is caused by coniferous reforestation: an artificial reforestation leads to an important change of macro conditions which can not be predicted by earlier data.

In order to analyze the residues of simulated land cover, we introduced a kind of "distance" between the simulated and the real land covers (prediction failures). The Garrotxes land cover is described as qualitative data but may be put on a landscape rank scale which goes from dense areas (1: forests) to open landscape corresponding to more intensive use (6: agriculture). Therefore, we grouped deciduous and coniferous forests. By this way, we defined a difference between two land cover values. A negative distance means a predicted landscape, "opening", while positive values express a predicted landscape, "closing" (that did not happen). The prediction failures occur outside stable areas which are concentrated along the western and southern limits of the studied area (public forests) and on the left bank (large pastures).

Data of Figure 13 show a contingency table of the model and the importance of the misclassification. Almost the half of false predicted area corresponds to a prediction failure of only one land cover category. In other words, half of residues are very close to reality on a thematic point of view. The most important misclassified areas (three or more ranks) are due to random phenomenoms.

Fig. 13: Prediction residues (\%) according to the distances between real and sim land cover, Garrotxes. (Data for correct prediction differ from those mentioned earlier because the two forest categories were grouped.)

\begin{tabular}{llll}
\cline { 2 - 4 } & $\begin{array}{l}\text { Combined } \\
\text { geomatic } \\
\text { model }\end{array}$ & $\begin{array}{l}\text { Polychotomous } \\
\text { regression model }\end{array}$ & $\begin{array}{l}\text { Multilayer } \\
\text { perceptron model }\end{array}$ \\
\hline Correct prediction & 74.16 & 74.27 & 75.62 \\
\hline 1 difference & 17.36 & 17.23 & 16.47 \\
\hline 2 differences & 4.29 & 4.67 & 4.23 \\
\hline 3 differences & 2.92 & 2.43 & 2.51 \\
\hline 4 differences & 1.28 & 1.40 & 1.17 \\
\hline
\end{tabular}

In Alta Alpujarra, the vegetation dynamics is slower and, consequently the land cover values are more static and can not be ranked on the same way.

Then, let us describe the accuracy of the localization of each land cover:this can be expressed by a fuzzy logic based comparison between real and simulat land cover. Unlike a pixel by pixel comparison, fuzzy logic comparison allows a small error in localization. Fuzzy validation does only improve the overall good prediction rates of about $2 \%$ for all models and the two data sets. This small gain may be explained by the qualitative nature of land cover. By 
deeply observing Figures $\mathbf{8}$ and $\mathbf{9}$, we can notice that one important factor for misclassifying is the layered representation of land cover. Inside each land cover type, any variability exist, but this fact is not included into the data base. This may be illustrated by an example on Garrotxes: Figure 8 shows in the south eastern part a large oblong area predicted as scrubs (same land cover as in 1980 and 1989). In reality, this area changed into a deciduous forest by a natural dynamic; this emphasizes a general problem when handling with qualitative data: the intraclass variability. In this case, scrubs became higher and higher and, at the same time, the floristic composition changed and Quercus ilex got the upper hand.

Another way to analyze model behaviour and results consists in intersecting simulated land cover maps. This was done for the Garrotxes: as shown in Figure 14, the correct predicted area obtained by intersection of the three simulated maps is about $66.5 \%$. This means a high consistency between the three models; individual prediction rates of each model are about 73 to $75 \%$. It is not surprising that these good predictions are higher on persistent and large areas like coniferous forests. The following columns show the good prediction rates obtained by the intersection of two model results (for pixels that are incorrectly predicted by the last model) or the good prediction rate of a single model (for pixels that are incorrectly predicted by the two other models).

Fig. 14: Prediction rates (\%) of simulated land cover by crossing simulated results, Garrotxes. CGM $=$ combined geomatic model; MPM = multilayer perceptron model; PRM = polychotomous regression model. Cropland that is less than $0.01 \%$ of area is not represented.

\begin{tabular}{|c|c|c|c|c|c|c|c|c|}
\hline \multirow{2}{*}{$\begin{array}{l}\text { Correct prediction } \\
\text { performed by }\end{array}$} & \multirow{2}{*}{$\begin{array}{l}\text { Every } \\
\text { model }\end{array}$} & \multicolumn{3}{|c|}{2 models } & \multicolumn{3}{|c|}{1 model } & \multirow[b]{2}{*}{ None } \\
\hline & & $\begin{array}{c}\text { MPM + } \\
\text { PRM }\end{array}$ & $\begin{array}{c}\text { CGM + } \\
\text { PRM }\end{array}$ & $\begin{array}{c}\text { CGM + } \\
\text { MPM }\end{array}$ & CGM & MPM & PRM & \\
\hline Coniferous forest & 85.35 & 1.65 & 0.40 & 0.68 & 0.96 & 1.75 & 0.76 & 8.53 \\
\hline Deciduous forest & 46.26 & 0.90 & 0.57 & 3.11 & 4.98 & 3.93 & 0.50 & 39.75 \\
\hline Scrubs & 32.38 & 5.92 & 2.64 & 2.50 & 7.75 & 3.89 & 1.03 & 43.89 \\
\hline Broom lands & 76.98 & 4.99 & 2.45 & 0.74 & 2.82 & 0.70 & 0.93 & 10.39 \\
\hline Grass pasture & 26.30 & 7.63 & 3.27 & 2.24 & 7.71 & 2.91 & 2.32 & 47.62 \\
\hline Grassland & 59.14 & 11.64 & 1.66 & 4.70 & 1.06 & 5.26 & 1.99 & 14.55 \\
\hline TOTAL & 66.49 & 3.75 & 1.42 & 1.54 & 3.23 & 2.33 & 0.92 & 20.32 \\
\hline
\end{tabular}

Figure 14 shows that the intersection of the two semi-automatic models have the most important good prediction rate other the couples of models $(3.75 \%)$. The intersection of each one with the combined geomatic model is less efficient. This means higher consistency between the polychotomous regression model and the multilayer perceptron model. On the other hand, Figure 14 also proves that the most important good prediction rate for a single model is made by the combined geomatic model $(3.23 \%)$. This means that the combined geomatic model and the two semi automatic models are complementary to each others.

In order to better understand the differences between the two semi-automatic models against the combined geomatic model, it is useful to analyze prediction rates according to land cover changes. We already said that prediction rate is better on the Spanish area, particularly when land cover is simulated by a semi-automatic model. This may appear poor compared to Null model (land cover persistence), but it is interesting to notice that the annual land cover change rate during the training period is different from the change rate between the two last dates. This average annual rate decreased moderately in Garrotxes (from $2.7 \%$ to $2.5 \%$ ) but increased in Alta Alpujarra Granadina (from $0.3 \%$ to $0.95 \%$ ).

The previous remarks seem to prove that the good prediction rates are related to the number and the velocity of land cover changes. Therefore we calculated LUCC budgets between the last two maps.

Fig. 15: Garrotxes real LUCC-budget 1989-2000 and 1989-2000 LUCC-budgets for simulated land cover in 2000. 


\begin{tabular}{lllllllllll} 
& Gain & Loss & $\begin{array}{l}\text { Total } \\
\text { change }\end{array}$ & Swap & $\begin{array}{l}\text { Abs value } \\
\text { of net } \\
\text { change }\end{array}$ & Gain & Loss & Total change & $\begin{array}{l}\text { Swap } \\
\text { Abs value of } \\
\text { net change }\end{array}$ \\
\hline Coniferous forest & 5.92 & 3.60 & 9.53 & 7.21 & 2.32 & 2.43 & 0.68 & 3.11 & 1.35 & 1.76 \\
\hline Deciduous forest & 6.20 & 0.51 & 6.71 & 1.01 & 5.70 & 2.40 & 0.08 & 2.47 & 0.15 & 2.32 \\
\hline Scrubs & 8.25 & 8.92 & 17.18 & 16.51 & 0.67 & 3.87 & 3.49 & 7.36 & 6.98 & 0.38 \\
\hline Broom land & 4.34 & 6.17 & 10.51 & 8.68 & 1.83 & 3.35 & 3.21 & 6.56 & 6.43 & 0.13 \\
\hline Grass pasture & 2.39 & 6.18 & 8.57 & 4.79 & 3.79 & 0.62 & 3.81 & 4.43 & 1.23 & 3.20 \\
\hline Grassland & 0.83 & 2.44 & 3.27 & 1.66 & 1.61 & 0.27 & 1.56 & 1.82 & 0.53 & 1.29 \\
\hline Agriculture & 0.01 & 0.13 & 0.14 & 0.01 & 0.12 & 0.00 & 0.11 & 0.11 & 0.00 & 0.11 \\
\hline Total & $\mathbf{2 7 . 9 5}$ & $\mathbf{2 7 . 9 5}$ & $\mathbf{2 7 . 9 5}$ & $\mathbf{1 9 . 9 3}$ & $\mathbf{8 . 0 2}$ & $\mathbf{1 2 . 9 3}$ & $\mathbf{1 2 . 9 3}$ & $\mathbf{1 2 . 9 3}$ & $\mathbf{8 . 3 4}$ & $\mathbf{4 . 5 9}$ \\
\hline
\end{tabular}

Polychotomous regression model

Multilayer perceptron model

\begin{tabular}{lllllllllll} 
& Gain & Loss & $\begin{array}{l}\text { Total } \\
\text { change }\end{array}$ & Swap & $\begin{array}{l}\text { Abs value } \\
\text { of net } \\
\text { change }\end{array}$ & Gain & Loss & Total change & Swap & $\begin{array}{l}\text { Abs value of } \\
\text { net change }\end{array}$ \\
\hline Coniferous forest & 2.76 & 0.21 & 2.96 & 0.41 & 2.55 & 2.84 & 0.09 & 2.93 & 0.18 & 2.75 \\
\hline Deciduous forest & 0.48 & 0.19 & 0.66 & 0.37 & 0.29 & 1.30 & 0.07 & 1.37 & 0.14 & 1.23 \\
\hline Scrubs & 0.53 & 1.70 & 2.23 & 1.06 & 1.17 & 1.50 & 3.12 & 4.62 & 3.01 & 1.61 \\
\hline Broom land & 2.97 & 0.53 & 3.50 & 1.06 & 2.44 & 2.87 & 1.25 & 4.13 & 2.51 & 1.62 \\
\hline Grass pasture & 0.37 & 3.62 & 4.00 & 0.75 & 3.25 & 0.23 & 3.65 & 3.88 & 0.47 & 3.41 \\
\hline Grassland & 0.17 & 0.91 & 1.08 & 0.34 & 0.74 & 0.21 & 0.66 & 0.88 & 0.43 & 0.45 \\
\hline Agriculture & 0.01 & 0.13 & 0.14 & 0.01 & 0.12 & 0.00 & 0.13 & 0.13 & 0.00 & 0.13 \\
\hline Total & $\mathbf{7 . 2 8}$ & $\mathbf{7 . 2 8}$ & $\mathbf{7 . 2 8}$ & $\mathbf{2 . 0 0}$ & $\mathbf{5 . 2 8}$ & $\mathbf{8 . 9 7}$ & $\mathbf{8 . 9 7}$ & $\mathbf{8 . 9 7}$ & $\mathbf{3 . 3 6}$ & $\mathbf{5 . 6 0}$ \\
\hline
\end{tabular}

The LUCC-budget for Garrotxes (Figure 15) shows an important total change (about 28 $\%)$ those swap part $(20 \%)$ is much more significant as its net change $(8 \%)$. In comparison to this real LUCC-budget, those performed by real land cover in 1989 but simulated land cover in 2000 are systematically lower; particularly, polychotomous regression and multilayer perceptron simulated land cover pull down land cover dynamics. Only the combined geomatic model leads to a proportion of "swap / net" changes close to the real ones. However the total amount of change is only half of the real one.

So, all of the models, but particularly the two semi-automatic models, simulate persistence and underestimate land cover changes. The following tables underline this observation. Figure 16 shows the correct prediction rate of each model depending on the number of land cover changes over three dates $(1974,1987$ and 2001) for the Spanish test area.

Fig.16: Correct prediction scores obtained by the three models in Alta Alpujarra Granadina depending on the number of land cover changes between 1974 - 1987 - 2001: persistence $(86.89 \%)$; one land cover change (12.83\%); two land cover changes $(0.28 \%)$.

\begin{tabular}{cccc}
\hline Land cover changes $\backslash$ & \multicolumn{3}{c}{ Number of land cover changes } \\
Model & Persistence & 1 change & 2 changes \\
& $86.89 \%$ & $12.83 \%$ & $0.28 \%$ \\
\hline $\begin{array}{c}\text { Combined geomatic } \\
\text { model }\end{array}$ & $83.9 \%$ & $61.5 \%$ & $22.2 \%$ \\
\hline
\end{tabular}




\begin{tabular}{cccc}
$\begin{array}{c}\text { Polychotomous } \\
\text { regression model }\end{array}$ & $98.0 \%$ & $45.6 \%$ & $1.5 \%$ \\
\hline $\begin{array}{c}\text { Multilayer perceptron } \\
\text { model }\end{array}$ & $96.0 \%$ & $41.6 \%$ & $2.0 \%$ \\
\hline
\end{tabular}

Figure 16 proves that land cover is simulated almost perfectly by each of the two semiautomatic models on areas with land cover persistence. The combined geomatic model is clearly less efficient when land cover does not change. It is areas for which land cover becomes different. The more land cover changes are numerous, the better the combined geomatic model predictions are. On the other hand, changes are so rare that predicting them is very difficult.

Fig.17: Prediction rates (\%) of simulated land cover by crossing simulated results, Garrotxes, depending on the number of land cover changes between $1980-1989-2000$ : persistence (58.87\%); 1 land cover change (30.16\%); two land cover changes $(10.97 \%)$. CGM = combined geomatic model; MPM = multilayer perceptron model; PRM = polychotomous regression model.

\begin{tabular}{|c|c|c|c|c|c|c|c|c|}
\hline \multirow{2}{*}{$\begin{array}{c}\text { Correct prediction } \\
\text { performed by }\end{array}$} & \multirow{2}{*}{$\begin{array}{c}\text { Every } \\
\text { models }\end{array}$} & \multicolumn{3}{|c|}{ 2 models } & \multicolumn{3}{|c|}{ 1 model } & \multirow{2}{*}{ None } \\
\cline { 3 - 10 } & & $\begin{array}{c}\text { MPM + } \\
\text { PRM }\end{array}$ & $\begin{array}{c}\text { CGM + } \\
\text { PRM }\end{array}$ & $\begin{array}{c}\text { CGM + } \\
\text { MPM }\end{array}$ & CGM & MPM & PRM & \\
\hline Persistence -58.87 & 93.50 & $\mathbf{2 . 8 9}$ & 0.96 & 0.79 & 0.47 & 0.50 & 0.32 & 0.57 \\
\hline 1 change -30.16 & 35.28 & 5.89 & 2.16 & 1.97 & $\mathbf{6 . 1 2}$ & 4.36 & 1.31 & 42.92 \\
\hline 2 changes -10.97 & 9.51 & 2.47 & 1.85 & 4.29 & $\mathbf{9 . 7 9}$ & 6.44 & 3.05 & 62.61 \\
\hline
\end{tabular}

Figure 17 shows the correct prediction rates of the models applied to Garrotxes depending on the number of land cover changes. It confirms the trends observed on the Spanish test area. First, we can see that the persistence over only two decades is significantly smaller (less than $60 \%$ ) than in Spain (about $87 \%$ over 27 years). We observe that less than 1 $\%$ of the whole area has two changes in Andalusia, whereas about $11 \%$ of the French Pyrenees is concerned with a double change of land cover. Data in figure 17 show that persistence is easy to predict. Intersecting the three maps, $93.5 \%$ of the studied area is correctly predicted by every models. The better prediction rate for couples of models is obtained by the two semi-automatic models $(2.89 \%$ - in bold). These common correct prediction scores pull down on area with land cover dynamics. Nethertheless, the combined geomatic model is the most efficient on area with land cover changes.

\section{Conclusion and outlook}

The authors underline that the three applied models perform very similarly. The total prediction scores are as better as the land cover is persistent. By intersecting model outputs, performing LUCC-budgets and comparing simulated land cover depending on land cover changes, we highlighted the proximity of the two semi automatic models compared to the combined geomatic model. This last one may be seen as a manual or directed model. It clearly appears that chaining semi automatic and manual supervised modelling steps can improve the simulations. Polychotomous regression and multilayer perceptron models work better if land cover is persistent. On the contrary, the combined geomatic model is closer to reality when land cover changes.

We also focused on some limiting criteria. First, qualitative land cover data do not take into account the variability inside one land cover type. This implicates that we need more training data. Another limiting point is the small number of training dates. The training step is performed with only two land cover maps and few criteria able to explain land cover changes.

The authors emphasize the fact that the models are based on a small number of data that are easily available so the application of the methodologies described in this paper to other areas should be easy to perform. To improve prospective land cover modelling, the authors apply the models to other areas characterized by high speed land cover changes (tropical deforestation) based on remote sensing data. Handling with various data sources and land 
cover dynamics may contribute to better know about the the ability of generalization of our modelling approaches. It would also be helpful to consider intra-class variance by using semiquantitative land cover data (covering rates) and to confront the models to other methodological approaches and available software.

\section{Acknowledges}

The authors are grateful to Ministerio de Ciencia y Tecnología (BIA 2003_01499), Plan Nacional de Investigación Científica, Desarrollo e Innovación Tecnológica and FEDER fund for supporting this research.

\section{References} Version 3.

Beale M., Demuth H. (1998): Neural Network Toolbox User's Guide, The Mathworks Inc. New York.

Bishop C.M. (1995): Neuronal Networks for pattern recognition, Oxford University Press,

Camacho Olmedo, M.T.(2003): "Cambios en el paisaje de la Alta Alpujarra granadina: determinación de los ritmos temporales y principales dinámicas con ayuda de un Sistema de Información Geográfica", Geografías para una sociedad global: diversidad, identidad y exclusión social, AGE. Universidad Autónoma de Barcelona.

Camacho Olmedo, M.T., García Martínez, P., Jiménez Olivencia, Y., Menor Toribio, J., Paniza Cabrera, A. (2002a): "Dinámica evolutiva del paisaje vegetal de la Alta Alpujarra granadina en la segunda mitad del siglo XX", Cuadernos Geográficos de la University of Granada, n³2, pp. 25-42.

Camacho Olmedo, M.T., García Martínez, P., Jiménez Olivencia, Y., Menor Toribio, J. Paniza Cabrera, A. (2002b): "La transformación de un paisaje de montaña: el proceso de abandono de la agricultura en la Alta Alpujarra granadina", in Los espacios rurales entre el hoy y el mañana, XI Coloquio de Geografía Rural, AGE. University of Cantabria, pp. 547-559.

Camacho Olmedo, M.T., García Martínez, P., Jiménez Olivencia, Y., Menor Toribio, J. Paniza Cabrera, A. (2002c): "La Alta Alpujarra granadina en la segunda mitad del siglo XX a través de la cartografía evolutiva de su paisaje: Dinámica vegetal y repoblación forestall", in: Los espacios rurales entre el hoy y el mañana, XI Coloquio de Geografía Rural, AGE. University of Cantabria, pp. 535-547.

Ferraty F., Paegelow M., Sarda, P. ( 2005): "Polychotomous regression: application to land cover prediction", in: Haerdle W., Mori Y., Vieu P. (coord.): Statistical case studies, Springer Verlag, e-book XploRe,13 p. http://www.xplore-stat.de/ebooks/ebooks.html

Garcia Martínez P (1999): La transformación del paisaje y la economía rural en la Alta Alpujarra Occidental, Editorial de la Universidad de Granada, 563 p.

Hornik, K. (1991): "Approximation capabilities of multilayer feedforward networks", Neural Networks, 4(2), pp. 251-257.

Hornik K. (1993): "Some new results on neuronal network approximation", Neural Networks, 6 (8), p 1069-1072.

Kooperberg C., Bose S., Stone J. (1997): "Polychotomous Regression", J. Amer. Statist. Assoc., 92, p 117-127. 
Lai, T., Wong, S. (2001): "Stochastic neural networks with applications to nonlinear time series", Journal of the American Statistical Association, 96(455), pp.968-981.

Métailié J.P., Paegelow M. (2004): "Land Abandonment and the Spreading of the Forest in the Eastern French Pyrenees in the Nineteenth to Twentieth Centuries", in: Mazzoleni S., Pasquale di G., Mulligan M., Martino di P., Rego F. (coord.): Recent Dynamics of the Mediterranean Vegetation and Landscape, Wiley; p. 219-236.

Mezzadri-Centeno, T. (1998) : La modélisation et la projection spatio-temporelle dans les SIG, Thèse de Doctorat. IRIT - University Toulouse 3, Toulouse.

Paegelow M. (2003): "Prospective modelling with GIS of land cover in Mediterranean mountain regions", 6th AGILE Conference on GIScience, april 24-26, Lyon, p. 519-529.

Paegelow M., Camacho Olmedo M.T. (2003): "Le processus d'abandon des cultures et la dynamique de reconquête végétale en milieu montagnard méditerranéen: L'exemple des Garrotxes (P.O., France) et de la Alta Alpujarra Granadina (Sierra Nevada, Espagne)", Sud Ouest Européen, 16, p. 113-130.

Paegelow M., Camacho Olmedo M.T.(2005): "Possibilities and limits of prospective GIS land cover modeling - a compared case study: Garrotxes (France) and Alta Alpujarra Granadina (Spain)", International Journal of Geographical Information Science; vol. 19, $n^{\circ} 6, p$ 697-722.

Paegelow, M., Camacho Olmedo M.T., Menor Toribio J (2002): "Modelizacion prospectiva del paisaje mediante Sistemas de Informacion Geografica", X Congreso de Metodos Quantitativos, Sistemas de Informacion Geografica y Teledeteccion. Asociación de Geógrafos Españoles.17-20 septembre,Valladolid, 10 p.

Paegelow M., Camacho Olmedo M.T., Menor Toribio J. (2003): "Modelizacion prospectiva del paisaje mediante Sistemas de Informacion Geografica", GEOFOCUS, 3; p. $22-$ 44 (http//geofocus.rediris.es).

Paegelow M., Camacho Olmedo M.T., Menor Toribio J. (2004): "Límites y aportaciones de los Sistemos de Información Geográfica para trazar la dinámica espacio-temporal del paisaje en áreas montañosas mediterráneas", in: Santos Preciado J.M.: Sistemas de Información Geográfica, Universidad nacional de Educación a Distancia, p. 396-402.

Paegelow M, Villa N., Cornez L., Ferraty F., Ferré L, Sarda P. (2004): "Modélisations prospectives de l'occupation du sol. Le cas d'une montagne méditerranéenne", Cybergéo, $\mathrm{n}^{\circ}$ 295, 6 décembre 2004, 19 p.

Parlitz U., Merkwirth C. (2000): "Nonlinear prediction of spatial-temporal time series", ESANN'2000 proceedings, Bruges, 26-28, p 317-322.

R Development Core Team (2005): $R$ : A language and environment for statistical computing, R Fundation for Statistical Computing, Vienna, Austria.

Saaty, T.L. (1977): "A Scaling Method for Priorities in Hierarchical Structures", J. Math. Psychology, 15, pp. 234-28.

Selleron G., Mezzadri-Centeno T. (2002): "Télédétection et logique floue : diagnostic et prospections temporelles de la déforestation sur un front pionnier tropical", Soc. Française de Photogrammétrie et Télédétection, $\mathrm{n}^{\circ} 167$ p 4-15, 2002.

Yager, R., R. (1988): "On Ordered Weighted Averaging aggregation operators in multicriteria decision making", IEEE Transactions on Systems, Man, and Cybernetics, 8(1), pp. 183-190. 
Villa N., Paegelow M., Cornez L., Ferraty F., Ferré L., Sarda P. (2006): "Various approaches for predicting land cover in Mediterranean mountains", Communication in Statistics, volume 36 , to come out.

White, H. (1989): "Learning in artificial neural network: a statistical perspective", Neural Computation.

Zadeh L.A. (1988): Fuzzy Logic, IEEE computer. 